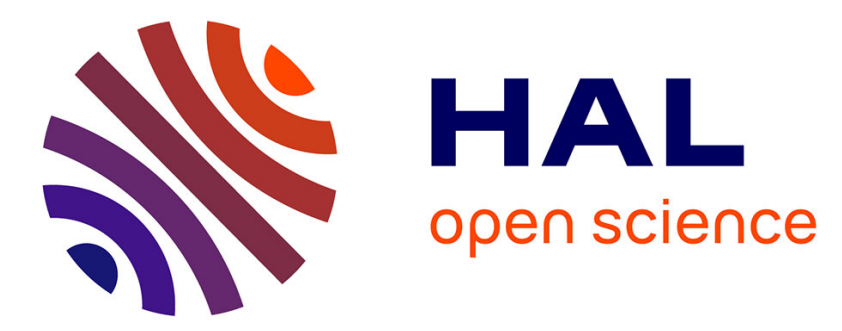

\title{
Annealing twin development during recrystallization and grain growth in pure nickel
}

Yuan Jin, Brian Lin, Marc Bernacki, Gregory S. Rohrer, Anthony D. Rollet, Nathalie Bozzolo

\section{- To cite this version:}

Yuan Jin, Brian Lin, Marc Bernacki, Gregory S. Rohrer, Anthony D. Rollet, et al.. Annealing twin development during recrystallization and grain growth in pure nickel. Materials Science and Engineering: A, 2014, 597, pp.295-303. 10.1016/j.msea.2014.01.018 . hal-00945387

\section{HAL Id: hal-00945387}

https://hal-mines-paristech.archives-ouvertes.fr/hal-00945387

Submitted on 30 Mar 2015

HAL is a multi-disciplinary open access archive for the deposit and dissemination of scientific research documents, whether they are published or not. The documents may come from teaching and research institutions in France or abroad, or from public or private research centers.
L'archive ouverte pluridisciplinaire HAL, est destinée au dépôt et à la diffusion de documents scientifiques de niveau recherche, publiés ou non, émanant des établissements d'enseignement et de recherche français ou étrangers, des laboratoires publics ou privés. 


\title{
Annealing twin development during recrystallization and grain growth in pure Nickel
}

\author{
Y. JIN ${ }^{1, \text { a }}$, B. LIN $^{2}$, M. BERNACKI ${ }^{1}$, G.S. ROHRER ${ }^{2}$, A.D. ROLLETT ${ }^{2}$, N. BOZZOLO ${ }^{1}$ \\ ${ }^{1}$ MINES ParisTech, CEMEF - Centre de Mise en Forme des Matériaux, CNRS UMR 7635, \\ BP 2071 rue Claude Daunesse 06904 Sophia Antipolis cedex, France \\ ${ }^{2}$ Carnegie Mellon University, 5000 Forbes Avenue, Pittsburgh, 15213, USA \\ ayuan.jin@mines-paristech.fr
}

\begin{abstract}
A $99.99 \%$ pure Ni sample, compressed to $25 \%$, was annealed in a SEM chamber and changes in the density of annealing twins were monitored in situ during recrystallization and grain growth. In addition to average microstructural measurements, the evolution of individual grains was also observed. Both the average annealing twin density in the recrystallized domain and the average annealing twin density per grain increased during recrystallization. The rate of increase in twin density correlates with the velocity of the recrystallization front. During grain growth, however, the average annealing twin density decreased. The in situ EBSD observations showed both the formation of new twins and the extension of existing twins during annealing. The observations reported here suggest that the existing models for annealing twin formation are incomplete.
\end{abstract}

Key words: Annealing twin, Recrystallization, Grain growth, In situ annealing, EBSD

\section{Introduction}

In 1926, Carpenter and Tamura [1] reported on annealing twin formation and annealing twins were commonly mentioned in articles containing metallography before this. Since then, annealing twins have been observed in almost all deformed and subsequently annealed F.C.C. metals except for aluminum.

Annealing twin boundaries affect many properties such as corrosion and fatigue resistance in a large variety of materials [2] because of their low energy [3]. Annealing twin boundaries, especially coherent twin boundaries, are fundamental for 'Grain Boundary Engineering' [4-6]. Even today metallurgists still do not agree on the mechanism of their formation. 
There are four schools of thought on annealing twin formation: i) the grain encounter model [7-9], ii) the stacking fault model [10] where stacking fault packets formed during grain boundary migration generate annealing twins [11], iii) the grain boundary dissociation model [11-13] which involves a general high angle boundary dissociating into a coherent twin boundary, an incoherent twin boundary and a low energy boundary to decrease the overall interfacial energy, and iv) the growth accident model [1,14-17]. The growth accident model, which asserts that a coherent twin boundary forms at a migrating grain boundary because of a stacking error, is supported by a majority of recent experimental results [18-21].

In the growth accident model, the grain boundary migration distance and the grain boundary migration velocity are two key factors promoting the generation of annealing twins. Gleiter [14] and Pande [15] independently used this idea to model annealing twin density. Gleiter's formulation was shown to be capable of accurately determining the annealing twin density [19]. The effect of prior deformation was introduced into Pande's model [21] but this and other prior work has mainly focused on the average annealing twin density evolution in the grain growth regime. The purpose of this work is to analyze annealing twin formation in individual grains during recrystallization and to quantify annealing twins during both recrystallization and grain growth. We present evidence that the annealing twin density increases during recrystallization, but decreases during grain growth.

\section{Experimental details}

Commercially pure nickel (99.99\% wt) was used in this experiment. A cylindrical sample, 5 $\mathrm{mm}$ in diameter and $3 \mathrm{~mm}$ in height, was first compressed at room temperature to a $25 \%$ height reduction. After deformation, the sample was metallographically prepared with a final mechanical polish using a $0.5 \mu \mathrm{m}$ colloidal $\mathrm{SiO}_{2}$ suspension and a $200 \mu \mathrm{m}$ thick slice was removed for study. The sample was annealed in situ at $400^{\circ} \mathrm{C}$ in a FEI XL30 ESEM microscope equipped with a TSL EBSD system. The heating device was a thin tantalum foil 
on which the sample was spot-welded [22], which allows very high heating and cooling rates $\left(100^{\circ} \mathrm{C} / \mathrm{s}\right)$ and enables precise control of short annealing times. EBSD orientation maps were recorded with a $0.5 \mu \mathrm{m}$ step size to compromise between spatial resolution and acquisition time. To capture the initial stages of the recrystallization regime, short annealing times $(2 s)$ were used at the start of the experiment. The heat treatment sequence is detailed in Fig.1. The OIM $^{\mathrm{TM}}$ software was used to analyze the EBSD data. The influence of sample thickness on grain boundary migration was not considered here. Annealing twin density, defined as the number of twin boundary intercepts per unit length, was calculated using Eq. 1 [23],

$$
\text { Twin density }=\frac{L_{t b}}{S} \times \frac{2}{\pi},
$$

where $L_{t b}$ is the twin boundary length and $S$ is the corresponding area. Note that measuring intercepts is unreliable when evaluating twin boundaries inside recrystallizing grains and therefore lengths of twin boundaries provided the basis for the results reported here. Also, all $\Sigma 3$ boundaries are included in order to avoid the uncertainty associated with estimating whether any given boundary segment is a coherent or incoherent twin.

Following typical practice, the recrystallized grains were defined in the EBSD maps by a criterion that the Grain Orientation Spread (GOS) was less than $1^{\circ}$ [24]. GOS is defined as the average of the misorientation between the orientation of each point inside a grain and the average orientation of that grain. For grain detection, the minimum misorientation angle to define a grain boundary was set to $5^{\circ}$ and twins were ignored. Additionally, grains smaller than 1 pixel were not considered. No additional clean up was performed.

\section{Experimental results}

\subsection{Recrystallization}

The series of EBSD maps in Fig. 2 illustrates the microstructural development during recrystallization. The white lines mark the annealing twin boundaries, which are defined by a 
misorientation of $60^{\circ}$ about the $<111>$ axis with a tolerance of $8.66^{\circ}$, according to Brandon's criterion [25].

The first map, recorded before the heat treatment, shows the heterogeneity of deformation. Recrystallizing grains first appeared in the most deformed areas where the quality of Kikuchi patterns was initially low (Fig. 3). As recrystallization progressed, the first recrystallization nuclei grew together and formed clusters while new grains continued to appear in less deformed areas. The recrystallized grains and grain clusters began to impinge before the end of recrystallization. The overall recrystallization kinetics are illustrated in Fig. 4. In the early stages, the recrystallization nuclei grew independently and the recrystallization fraction increased rapidly. As impingement occurred, the recrystallized grains formed clusters, and recrystallization fronts migrated at the rim of the clusters, effectively reducing the transformation rate. The incubation time for recrystallization was negligible in this case.

\subsubsection{Annealing twin density evolution in individual grains during recrystallization}

For the purpose of tracking the evolution of individual grains, four recrystallized grains (colored red in Fig. 5) were selected. Annealing twins were generated very early in the recrystallization process. As the recrystallized grains grew into the deformed matrix, more annealing twins were generated (see Fig. 5). However, after impingement of the recrystallized grains, fewer annealing twins were generated.

The change in the size (equivalent circle diameter) of the four sampled grains with time is described in Fig. 6(a). Despite the different grain sizes, the individual grains exhibit the same trend of first increasing in size and then stagnating before the end of recrystallization. The annealing twin density per grain was calculated with Eq. 1 with the twin boundary length in the grain and the area of the grain at each of the annealing steps (Fig. 6(b)).

The twin densities in the first three selected grains exhibit a non-linear relationship with the equivalent circle diameters (Fig. 6(c)). More precisely, the twin density increased most 
rapidly at the beginning of recrystallization and the rate of increase decreased monotonically with recrystallized fraction. Meanwhile, the twin density in the fourth individual grain exhibited a different trend from the others. This grain was in contact with deformed areas until the end of recrystallization so new twins were generated continuously as it increased in size.

Figure 7 shows the rate of increase of annealing twin density, i.e. the slope of Fig. 6(b), as a function of the growth rate of recrystallizing grains, i.e. the slope of Fig. 6(a). At the early stages of recrystallization, both the sizes of the recrystallized grains and the annealing twin densities increased at the highest rate. Later, the sizes of the recrystallized grains increased more slowly and fewer annealing twins were generated. This trend is easily understood because rapid changes occur during the initial unimpeded growth of recrystallizing grains into a deformed matrix, but the rate decreases after the recrystallized grains impinge.

In our in situ annealing series, three mechanisms appear to contribute to changes in the annealing twin density in individual grains. The first is that new annealing twins are generated as recrystallized grains increase in size. The second is that annealing twin boundaries intersecting migrating recrystallization fronts are extended in length as the recrystallization front advances. Both mechanisms are illustrated in Fig. 8(a). In addition, a third phenomenon that derives from the three-dimensional nature of the sample, contributes to an apparent increase in twin density. As shown in Fig. 8(b), in the yellow circle, the red grain and the green grain are twin related, even though they appear to be separated by the deformed matrix. They are actually two pieces of the same twinned grain that are connected below the section plane. The twinning event apparently occurred underneath the observed section plane. This phenomenon is actually another case of twin boundary extension mentioned above, but complicated by the irregular shape of the recrystallization front which results in disjoint parts of the twin-related grains reaching the observation surface at different times. Contrary to the 
mechanisms illustrated in Fig. 8(a), this is more likely to happen during recrystallization than during grain growth. This is because local fluctuations in the stored energy can cause recrystallizing grains to develop convex shapes that are unlikely to occur during grain growth, i.e. a recrystallization front can migrate in the opposite direction to its center of curvature.

To summarize, as the recrystallization proceeds, the deformed matrix shrinks, the average stored energy level decreases and recrystallized grains impinge on each other forming clusters, thus slowing down their growth rate in both $2 \mathrm{D}$ and $3 \mathrm{D}$. As the rate of recrystallization slows, fewer twin boundaries are created and the rate of extension of existing twins is also slowed. Additionally, fewer new annealing twin boundaries are formed by the emergence of twin boundaries from below the section plane. Thus a correlation exist between recrystallization front migration rate and the rate of creation of annealing twin length.

\subsubsection{Average annealing twin density evolution during recrystallization}

Fig. 9(a) illustrates the average recrystallized grain size evolution. The average grain size reached after the subsequent grain growth anneal is also shown in this figure. The equivalent grain diameter is the arithmetic mean of the circle-equivalent diameters of the recrystallized grains. The grain size evolution is consistent with the recrystallization kinetics. At the beginning of recrystallization, the recrystallized grains grew independently so that the average grain size increased rapidly. After impingement, the average grain size increased more slowly.

Here, using Eq. 1 with the twin boundary length in all the recrystallized grains and the entire recrystallized area, we calculated the annealing twin density in recrystallized grains. Fig. 9(b) shows that the average annealing twin density in the recrystallized grains increases linearly with the average recrystallized grain size. The rate of increase of the average annealing twin density in the same period is also proportional to the average grain boundary migration rate, as shown in Fig. 9(c). 
The correlation between the average twin density and the average grain size, Fig. 9(b), differs from the non-linear behavior of individual grains shown in Fig. 6. There are two factors that contribute to this difference. First, the continual appearance of small recrystallized grains that nucleate or simply emerge from below the surface slows down the increase of the average recrystallized grain. Second, as illustrated in Fig. 5, annealing twins are generated almost as soon as recrystallized grains appear on the observation surface. The annealing twin density in the recrystallized grains after the $2 \mathrm{~s}$ heat treatment is indeed higher than $60 \mathrm{~mm}^{-1}$, which means there were many annealing twins generated in the very early stages of recrystallization. Thus, the continual appearance of recrystallized grains effectively smoothes the rate of increase in annealing twin density.

To summarize, both annealing twin density in the individual grains and the average twin density in the entire analyzed domain increased during recrystallization. However, the creation of annealing twins in individual grains is clearly sensitive to the decrease in migration rate of the recrystallization front.

The growth accident model suggests that annealing twins are generated during grain boundary migration. The important factors that determine the annealing twin generation frequency are grain size, grain boundary migration velocity, grain boundary energy and twin boundary energy [2].

As mentioned previously, Gleiter [14] and Pande [15] independently established models based on this mechanism to predict annealing twin density. Gleiter's model provides a twin generation probability, $R$. Based on a simplifying assumption of constant migration rate (of recrystallization fronts), the number of twins generated is proportional to $R$, which means that the twin density is also proportional to $R . \quad R$ depends on mainly two factors, Eq. 2: the activation enthalpy for migration $(Q)$ and the grain boundary migration driving force, which 
is equal to the difference in Gibbs free energy $\left(\Delta G^{\circ}\right)$ across the recrystallization front during recrystallization.

$$
R=\exp \left\{\frac{-Q}{\left(\frac{\pi \varepsilon^{2} h^{2}}{Q \gamma_{t}}-1\right) k T}\right\} \exp \left\{\frac{\ln \frac{\Delta G^{\circ}}{k T}}{\left(\frac{\pi \varepsilon^{2} h^{2}}{Q \gamma_{t}}-1\right)}\right\} .
$$

$\varepsilon$ is the energy of a step on the $\{111\}$ plane. $h$ is the height of a twin nucleus. $\gamma_{t}$ is the surface energy of a coherent twin boundary. $k$ is Boltzmann's constant and $T$ is the absolute temperature. Gleiter's model does not have any adjustable parameters. However, the value of $R$ is sensitive to certain parameters, such as $\varepsilon$, and accurate values are not available for these parameters, which means that some fitting is required.

Pande's model is derived from the following assumption:

$$
\Delta N \propto \Delta D \times F .
$$

where $\Delta N$ is the increment of annealing twin boundary number per grain, $F$ is the grain boundary migration driving force and $\Delta D$ is the variation of grain size. Since the twin density $P$ is equal to $N / D$, the twin density decreases when the number of twins per grain $(N)$ increases less rapidly than the grain size $(D)$.

Assuming that the driving force only depends on the average grain boundary curvature, the twin density $P$ is obtained as a function of the arithmetic mean of grain size $\langle D\rangle$,

$$
P=\frac{1}{\langle D\rangle} K \gamma_{g} \ln \frac{\langle D\rangle}{D_{0}}
$$

where $\gamma_{g}$ is the grain boundary energy, $D_{0}$ is the minimum critical grain size for the formation of the first annealing twin and $K$ is a constant which is generally fitted to experimental data.

Both of these models are based on the annealing twin formation mechanism in an individual grain. The results presented here show that during recrystallization, twin boundary 
propagation or extension also contributes to the annealing twin density evolution. Because neither of these models accounts for the extension of existing twin boundaries, they are not suitable for predicting annealing twin density evolution during recrystallization, especially when making comparisons to average experimental data.

\subsection{Grain Growth}

The in situ recrystallization experiment was performed at $400^{\circ} \mathrm{C}$. However, because the driving force is so much lower, grain growth is a much slower process. Therefore, the annealing temperature was increased gradually until grain growth was detectable, as shown in

Fig.1 (b). Because the temperature was adjusted in a relatively small range, the influence of annealing temperature on annealing twin fraction reported by Randle [26] and Brons [27] was not considered here. The final grain size (arithmetic mean) is shown in Fig. 9(a) and the evolution of the average annealing twin density in the grain growth regime is shown in Fig. 10. Here we used Eq. 1 with the twin boundary length in the entire analyzed domain and the area of the domain to calculate the average twin density. In contrast to the recrystallization regime, the twin density decreased continually during grain growth. Despite the non-constant annealing temperature, it is still possible to fit the experimental data with the original version of Pande's model [15] (Eq. 4). By using $\gamma=0.994 \mathrm{Jm}^{-2}$ [28], parameters $K$ and $D_{0}$ could be identified mathematically by an inverse method. We obtained $K=0.94 m^{3} J^{-1}$ and $D_{0}=2.5 \mu \mathrm{m}$. These values are similar to those quoted by Cahoon [18]. The identified value of $D_{0}$ is in the right range of magnitude as compared to the smallest detectable grain size to trigger twin generation that was observed in the recrystallization regime.

The decrease in annealing twin density can be attributed to the disappearance mechanisms shown in Fig. 11. In both examples, small grains containing several twin boundaries were consumed by large grains, which grew without producing new twins. Such a microstructural evolution is of course energetically favorable. Meanwhile, this is not the only possible 
annealing twin evolution mechanism observed during grain growth. The shrinkage of twin lamellae caused especially by the migration of incoherent twin boundary segments was reported previously in a Pb-based alloy [20] and in 304L stainless steel [23].

To illustrate the variation among materials, Fig. 12 shows an example of annealing twin formation at a triple junction in 304L stainless steel, also observed in an in situ annealing experiment. This is a common observation in this material, but rarely occurs in pure nickel.

\section{Discussion}

During grain growth, grains increase in size without producing new annealing twins. Two factors can explain this difference. First, the lower driving forces in grain growth, compared to recrystallization, lead to much slower grain boundary migration. Li [21] and Bozzolo [29] suggest that grain boundary migration velocity promote annealing twin generation. The effect of grain boundary migration velocity is also implicit in Pande's and Gleiter's models through the effect of the driving force amplitude. The second factor is linked to the grain boundary curvature. As illustrated in Fig. 13, for a convex grain boundary, once a coherent twin boundary forms on a $\{111\}$ facet of the grain boundary by a stacking fault, it can propagate easily through the grain. However, for a concave boundary, Shockley partial dislocations must terminate the newly formed coherent twin boundary segment. These dislocations form incoherent twin boundaries. Energetically, this configuration is less favorable than the coherent twin boundary formed behind the convex boundary, as incoherent twin boundaries have much higher interfacial energy than coherent twin boundaries [3]. Only in the recrystallization regime can grain boundaries migrate with negative curvature because of the stored energy that typically dominates over curvature. During grain growth, only at triple junctions can coherent twin boundaries propagate through a grain but this mechanism was not observed in this experiment. Grain boundary migration velocity and grain boundary curvature 
have a synergistic effect on annealing twin generation. This rationale explains why annealing twins are mostly generated during recrystallization.

In the present work, different annealing twin evolution mechanisms were observed during both recrystallization and grain growth. Neither Gleiter's model nor Pande's model accounts for all of these mechanisms. In the future we aim to address this gap with both mean field [30] and full field [31,32] modeling.

\section{Conclusion}

In situ annealing experiments on a $25 \%$ compressed $99.99 \%$ pure nickel sample were used to study annealing twin development in both the recrystallization and grain growth regimes. Individual grains were measured in addition to the overall microstructure. We drew the following conclusions:

- The average annealing twin density, defined as the number of twin boundary intercepts per unit length, increased during recrystallization and decreased during grain growth, which is consistent with our previous observations in 304L stainless steel [23].

- In the recrystallization regime, the correlation between the annealing twin density and the grain size in the overall microstructure differs from this correlation in individual grains. In individual grains, the twin density is more sensitive to the decrease in grain growth velocity. When the growth of the individual recrystallized grains decelerates, the creation of annealing twin density in these grains decelerates more sharply, because of:

i) reduced annealing twin boundary propagation,

ii) fewer annealing twin boundaries formed by the propagation of twin boundary from below the observed section. 
- In the grain growth regime, large grains consume small grains and their twins without producing many new twin boundaries. This phenomenon is the main factor that decreases the annealing twin density in the grain growth regime.

- The existing models for annealing twin formation cannot account for all of the mechanisms reported here, unless one differentiates between recrystallization and grain growth.

- Curvature driven boundary migration by itself is not sufficient to generate annealing twins. Therefore twin formation mechanisms based solely on migration appear to be incorrect. Twin formation is only observed for boundaries migrating into and recrystallizing deformed regions. Therefore twin formation mechanisms need to account for this difference in driving force, whether via the presence of dislocations or via inverse curvature. Certain formation mechanisms, like annealing twins formed on propagating $\{111\}$ steps and then moving inside the grain as proposed by Mahajan et al. [33], are not observed at all.

\section{Acknowledgements}

This work was funded by the French National Research Agency (ANR project called FORMATING: ANR-11-NS09-001-01) and the Materials World Network of the US National Science Foundation under grant number DMR-1107986. The authors would like to thank especially S. Jacomet for her help in carrying out the in situ annealing experiments. 


\section{References}

[1] H. Carpenter And S. Tamura, 'The formation of twinned metallic crystals', Proc. R. Soc.Lond. A113, 161-182(1926).

[2] B.B. Rath, M.A. Imam and C.S. Pande, 'Nucleation and growth of twin interfaces in FCC metals and alloys', Mater. Phys. Mech. 1, 61-66 (2000).

[3] D.L. Olmsted, S.M. Foiles, E.A. Holm, 'Survey of computed grain boundary properties in face-centered cubic metals: I. Grain boundary energy’, Acta Mater. 57, 3694-3703 (2009).

[4] G. Palumbo, E.M. Lehockey, and P. Lin, 'Application for Grain Boundary Engineered Materails', JOM, Feb, 40-43 (1998).

[5] V. Randle, 'Twinning-related grain boundary engineering', Acta Mater. 52, 40674081(2004).

[6] M. Kumar, C.A. Schuh, 'Preface to the viewpoint set on grain boundary engineering', Scripta Mater. 54, 961-962(2006).

[7] W.G. Burgers, 'Simulation Crystals and Twin-formation in Recrystallized Aluminum', Nature, 157, 76-77 (1946).

[8] W.G. Burgers, 'Cystal growth in the solid state (Recrystallization)', Physica, 15, 92-106 (1949).

[9] J.P. Nielsen, 'The origin of annealing twins', Acta Metall. 15, 1083-1085 (1967)

[10] S. Dash, N. Brown, 'An investigation of the origin and growth of annealing twins', Acta Metall. 11, 1067-1075 (1963).

[11] M.A. Meyers, L.E. Murr, 'A model for the formation of annealing twins in F.C.C. metals and alloys', Acta Metall. 26, 951-962 (1978).

[12] P.J. Goodhew, 'Annealing twin formation by boundary dissociation', Metal Sci. 13, 108112 (1979).

[13] M. Kumar, A.J. Schwartz, W.E. King, 'Microstructural evolution during grain boundary engineering of low to medium stacking fault energy fcc materials', Acta Mater. 50, 2599$2612(2002)$.

[14] H. Gleiter, 'The formation of annealing twins', Acta Metall. 17, 1421-1428 (1969).

[15] C.S. Pande, M.A. Imam, B.B. Rath, 'Study of annealing twins in FCC metals and alloys', Met. Trans. A 21, 2891-2896 (1990).

[16] E. Burke, 'The formation of annealing twins', Trans. Am. Inst. Min. Engrs 188, 13241328 (1950).

[17] R. L. Fullman And J. C. Fisher, 'Formation of annealing twins during grain growth', J. appl. Phys. 22, 1350-1355 (1951).

[18] J.R. Cahoon, Q. Li, N.L. Richards, 'Microstructural and processing factors influencing the formation of annealing twins', Mat. Sci. Eng. A 526, 56-61 (2009).

[19] Q. Li, J.R. Cahoon, N.L. Richards, 'On the calculation of annealing twin density', Scripta Mater. 55, 1155-1158 (2006).

[20] K.H. Song, Y.B. Chun, S.K. Hwang, 'Direct observation of annealing twin formation in a Pb-base alloy', Mat. Sci. Eng. A 454-455, 629-636 (2007).

[21] Q. Li, J.R. Cahoon, N.L. Richards, 'Effects of thermo-mechanical processing parameters on the special boundary configurations of commercially pure nickel', Mat. Sci. Eng. A 527, 263-271 (2009).

[22] N. Bozzolo, S. Jacomet, R.E. Logé, 'Fast in-situ annealing stage coupled with EBSD: A suitable tool to observe quick recrystallization mechanisms', Mater. Character. 70, 28-32 (2012).

[23] Y. Jin, M. Bernacki, G.S. Rohrer, A.D. Rollett, B. Lin, N. Bozzolo, 'Formation of annealing twins during recrystallization and grain growth in 304L austenitic stainless steel', Mater. Sci. Forum 753, 113-116 (2013). 
[24] M.H. Alvi, S.W. Cheong, J.P. Suni, H. Weiland, A.D. Rollett, 'Cube texture in hot-rolled aluminum alloy 1050 (AA1050) - nucleation and growth behavior', Acta Mater. 56, 30983108, 2008.

[25] D.G. Brandon, 'The structure of high-angle grain boundaries', Acta Metall. 14, 14791484, 1966.

[26] V. Randle, P.R. Rios, Y. Hu, 'Grain growth and twinning in nickel', Scripta Mater. 58, 130-133 (2008).

[27] J.G. Brons, G.B. Thompson, 'A comparison of grain boundary evolution during grain growth in fcc metals', Acta Mater. 61, 3936-3944 (2013).

[28] L.E. Murr, 'Temperature coefficient of twin-boundary energy: The determination of stacking fault energy from the coherent twin-boundary energy in pure F.C.C. metals', Scripta Metall. 6, 203-208 (1972).

[29] N. Bozzlo, N. Souai, R.E. Logé, 'Evolution of microstructure and twin density during thermomechanical processing in a $\gamma-\gamma$ ' nickel-based superally', Acta Mater. 50, 5056-5066 (2012).

[30] P. Bernard, S. Bag, K. Huang, R.E. Logé, 'A two-site mean field model of discoutinuous dynamic recrystallization’, Mat.Sci.Eng. A. 528, 7357-7367 (2011).

[31] M. Bernacki, Y. Chastel, T. Coupez, R.E. Logé, 'Level set framework for the numerical modeling of primary recrystallization in polycrystalline materials', Scripta Mater. 58, 11291132 (2008).

[32] M. Bernacki, R.E. Logé, T. Coupez, 'Level set framework for the finite-element modeling of recrystallization and grain growth in polycrystalline materials', Scripta Mater. 64, 525-528 (2011).

[33] S. Mahajan, C.S. Pande, M.A. Imam, B.B. Rath, 'Formation of annealing twins in F.C.C. crystals', Acta Mater. 45, 2633-2638 (1997). 


\section{Figures}

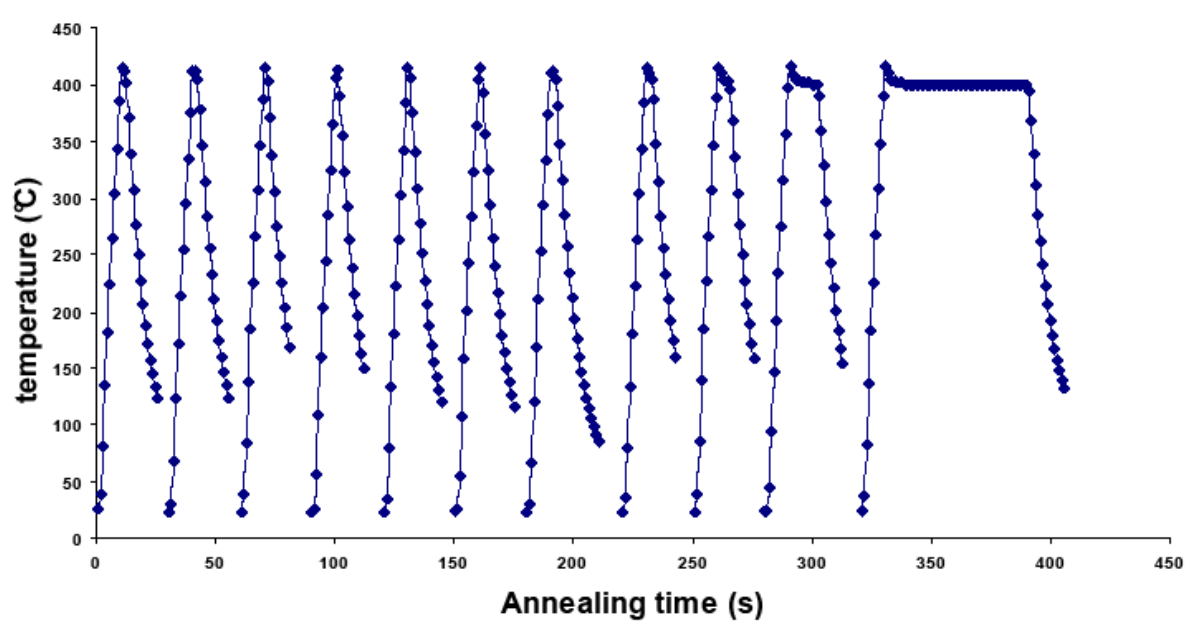

(a)

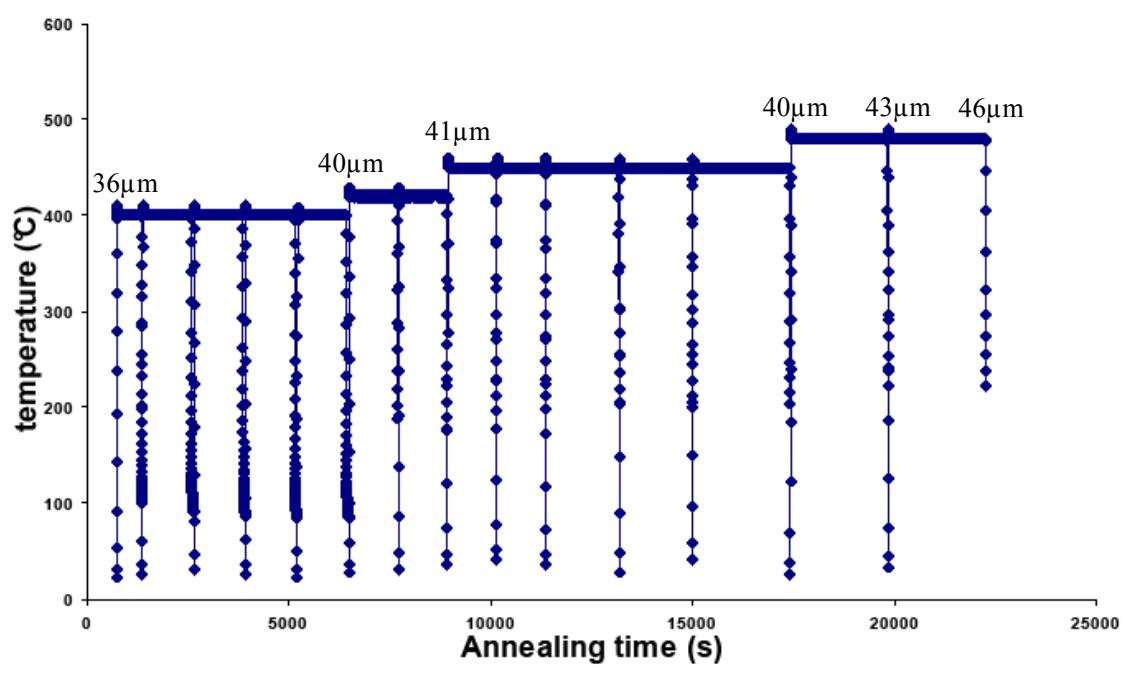

(b)

Fig. 1. In situ heat treatment sequence for the (a) recrystallization and (b) grain growth regimes. The area average grain sizes corresponding the main annealing steps are indicated. 


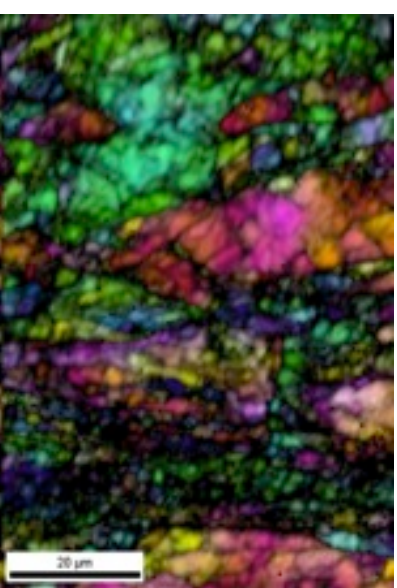

$0 \mathrm{~s}$

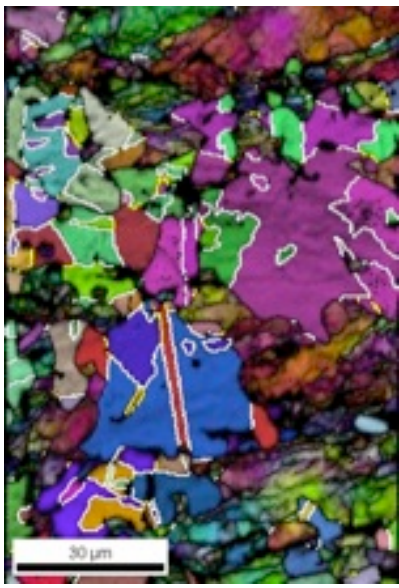

$7 \mathrm{~s}$

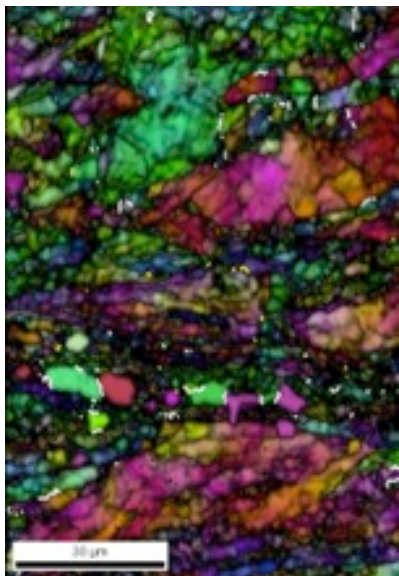

$2 \mathrm{~s}$

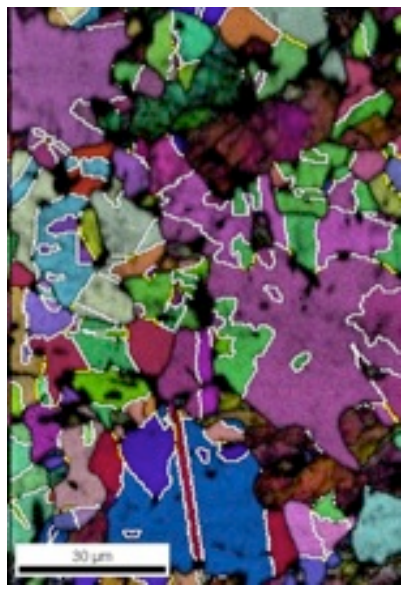

$18 \mathrm{~s}$

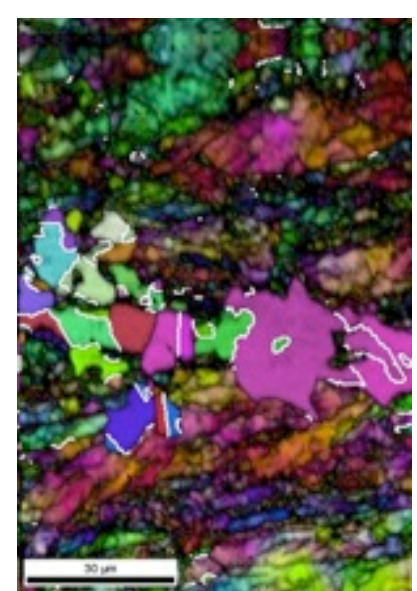

$4 \mathrm{~s}$

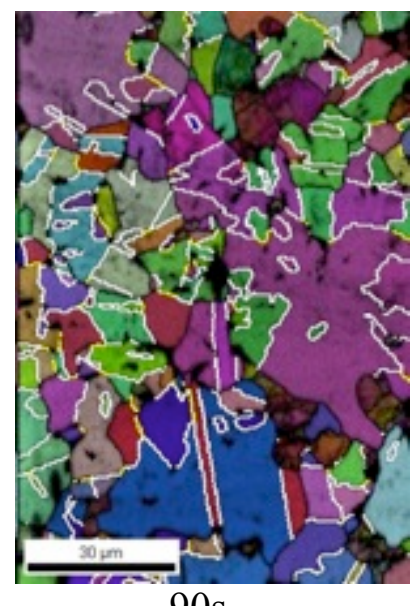

$90 \mathrm{~s}$
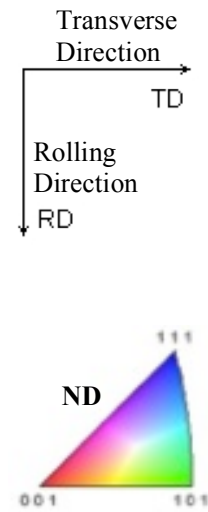

Fig. 2. In situ EBSD maps during recrystallization. For each state, the microstructure is shown by combining an orientation colour-code (radial direction ND (Normal Direction) projected in the standard triangle) and a grey scale according to the Kikuchi pattern quality. The accumulated annealing time at $400^{\circ} \mathrm{C}$ is shown under each map. 


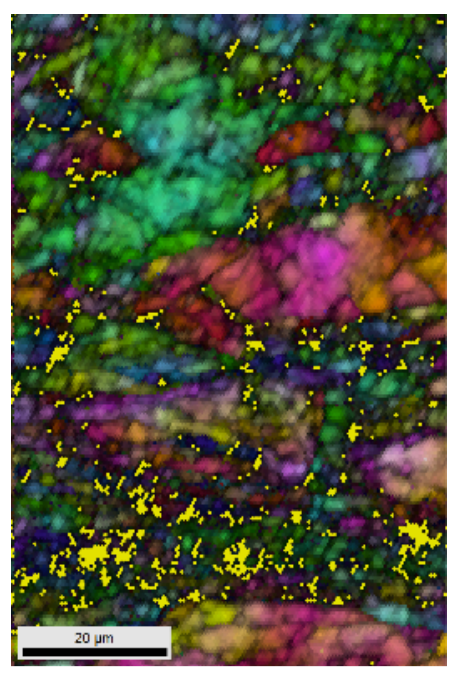

(a)

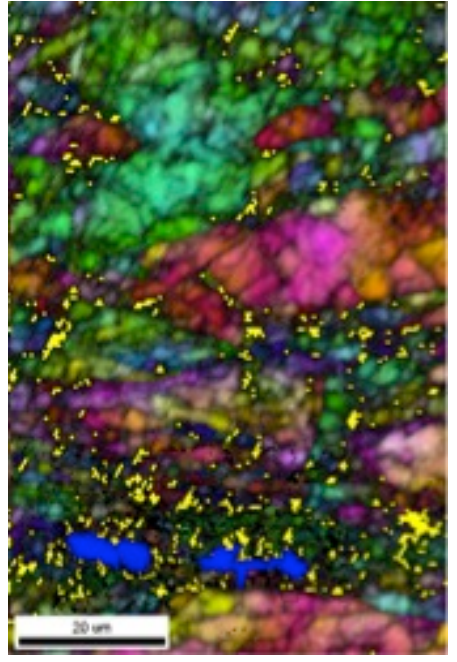

(b)

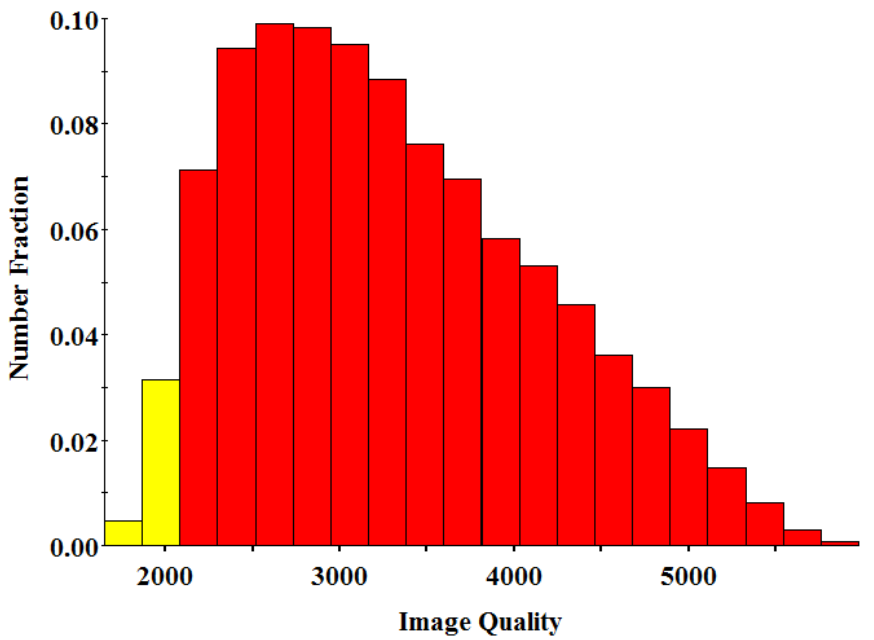

(c)

Fig. 3. (a) EBSD map of the initial state, the microstructure is shown by combining an orientation colour-code (same as in Fig.2) and a grey scale according to the Kikuchi pattern quality. The yellow pixels belong to the first two bins in the corresponding image quality distribution. (b) Figure (a) overlapped with the two recrystallized grains that appeared after the first heat treatment (colored blue). (c) Image quality distribution 


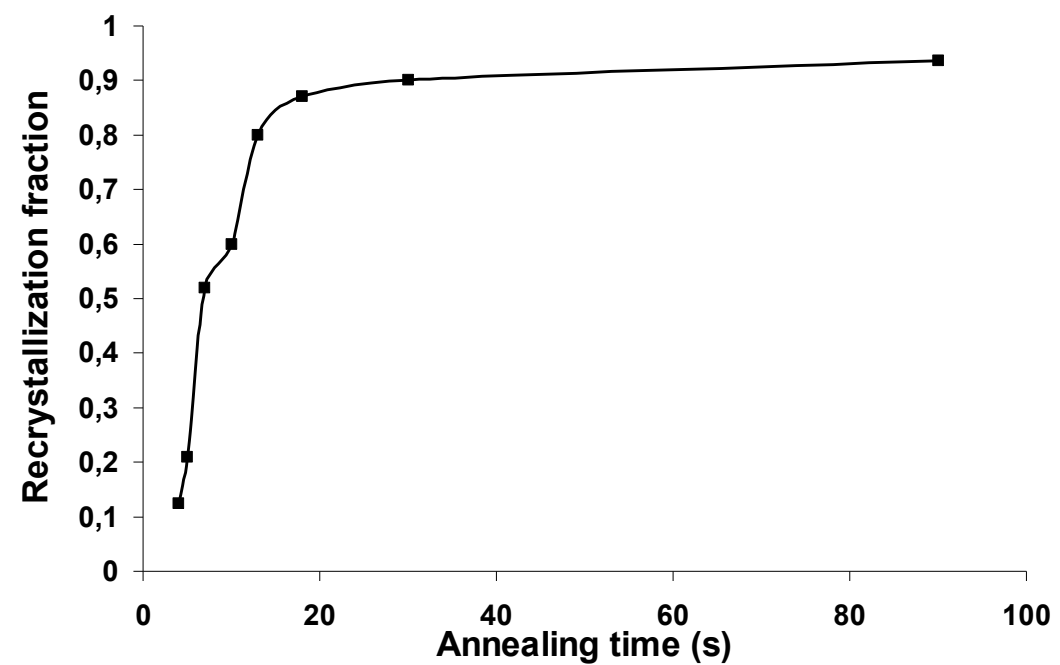

Fig. 4. Recrystallized fraction as a function of annealing time at $400^{\circ} \mathrm{C}$. 

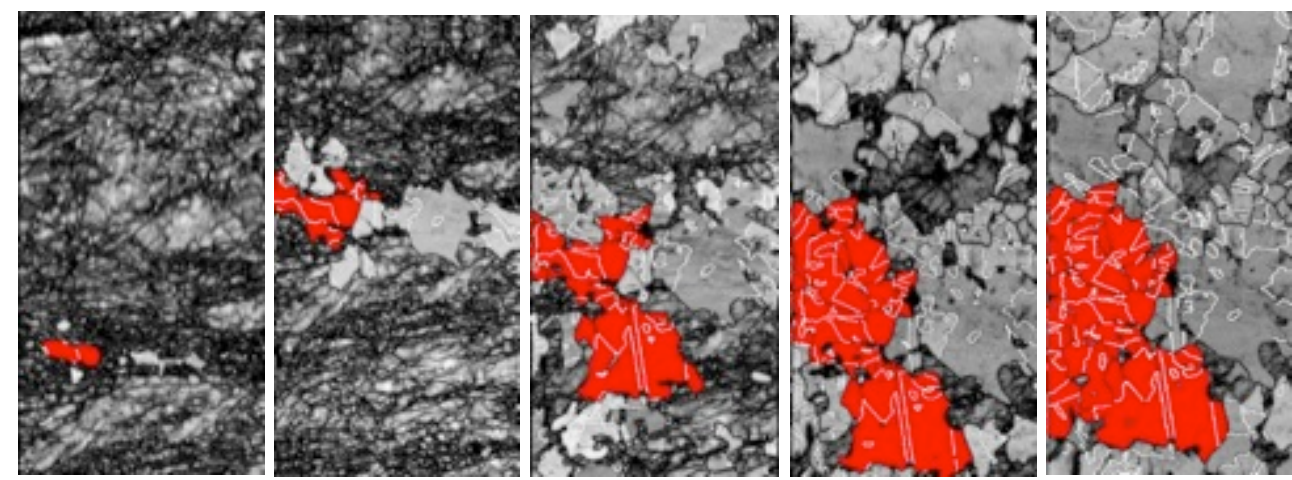

(Grain1-2s)
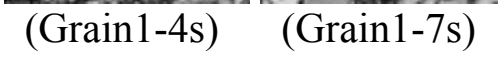

(Grain1-18s) (Grain1-90s)
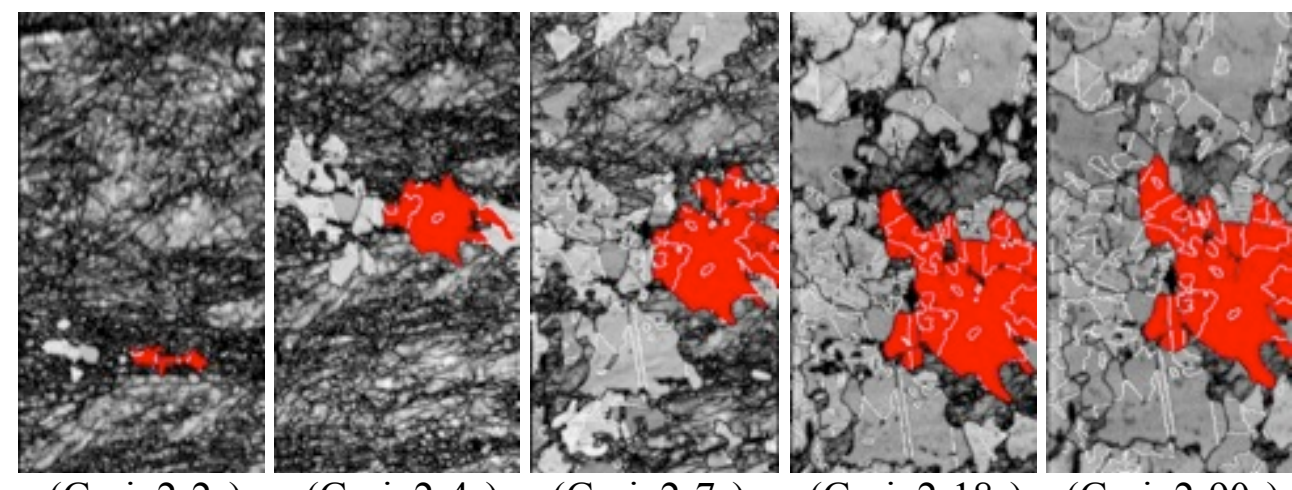

(Grain2-2s)
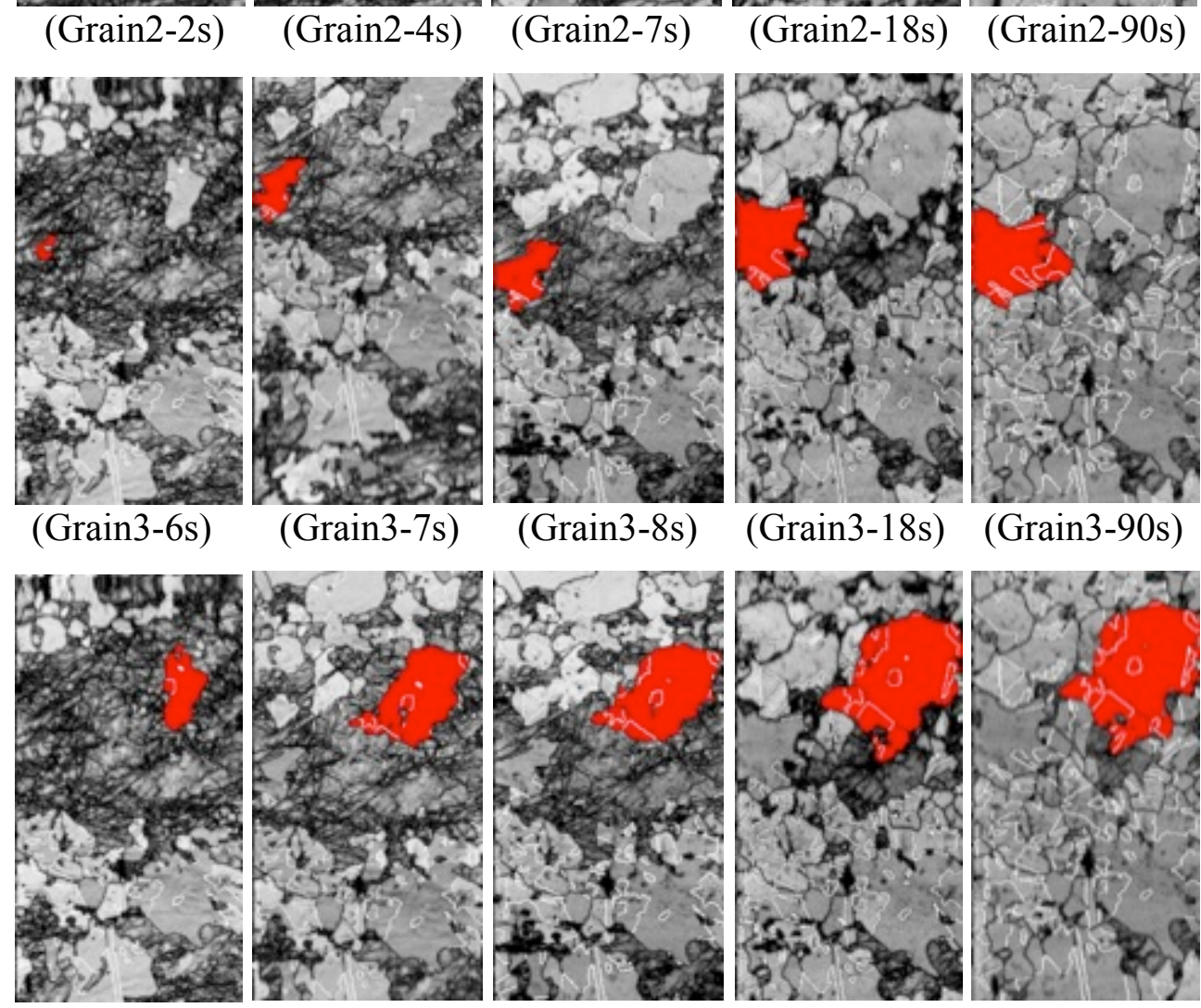

(Grain4-6s)

(Grain4-7s)

(Grain3-8s)

(Grain3-18s) (Grain3-90s)

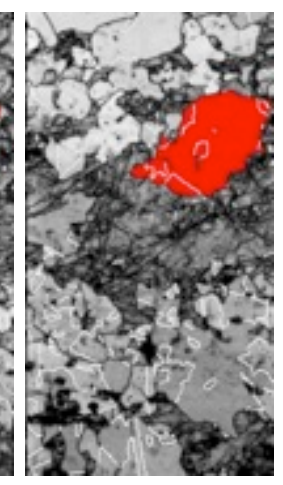

(Grain4-8s)

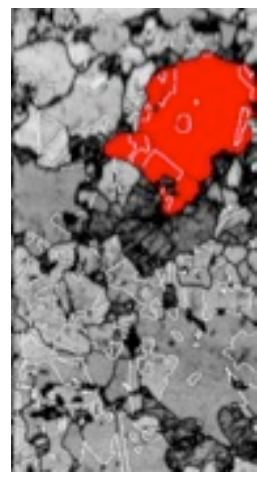

(Grain4-18s)

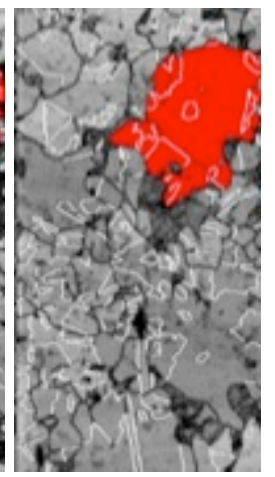

(Grain4-90s)

$30 \mu \mathrm{m}$

Fig. 5. Individual grain evolution. Selected grains (one per row) are colored red in the EBSD maps (grey scale shows the Kikuchi pattern quality). The accumulated annealing time is shown under each map. The thick white lines denote $\Sigma 3$ boundaries. 


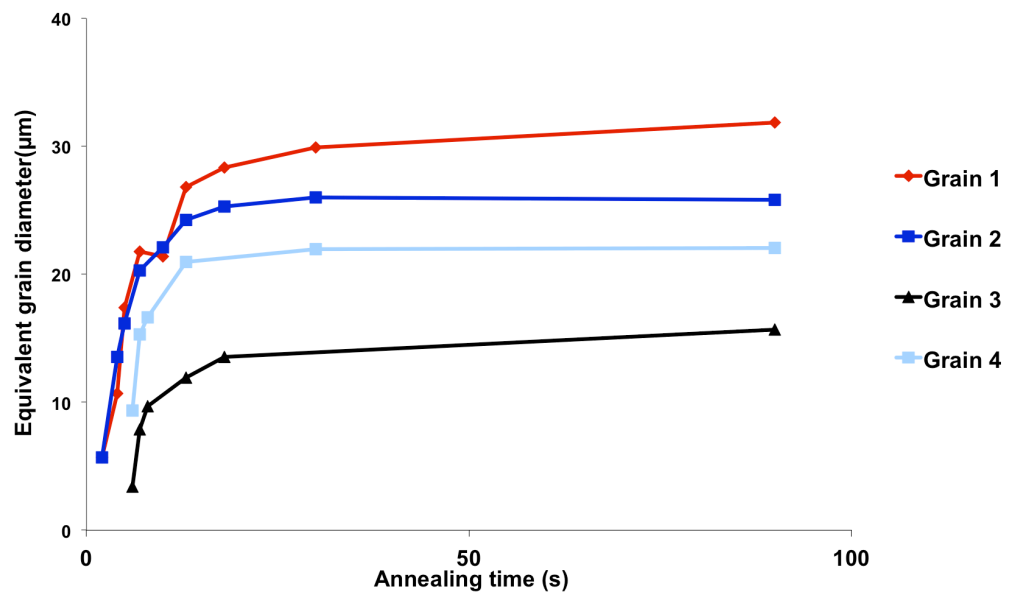

(a)

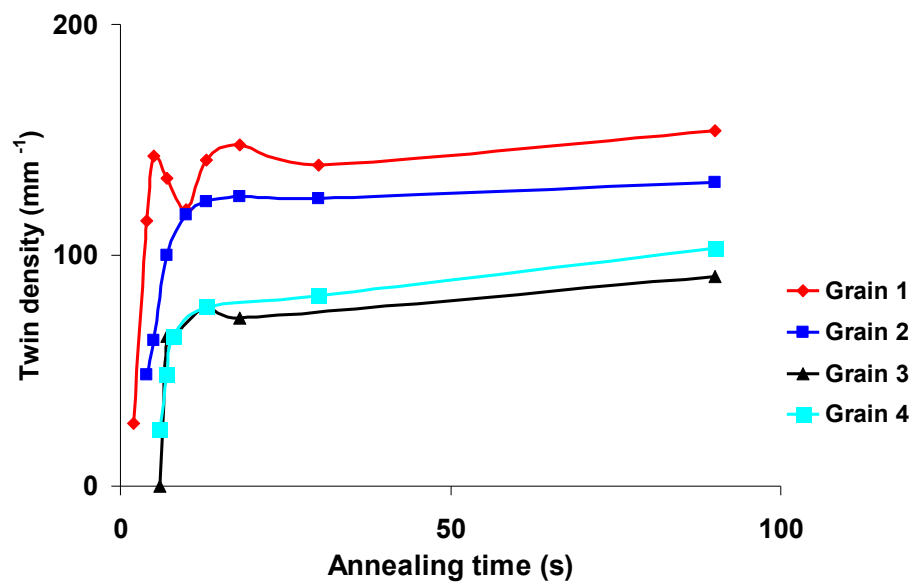

(b)

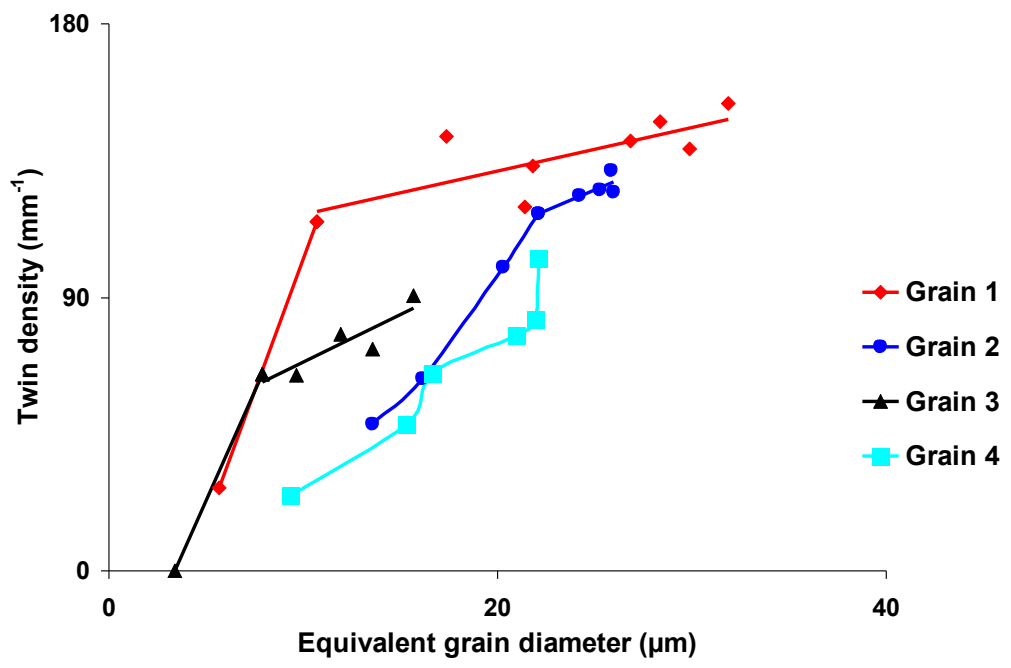

(c)

Fig. 6. Individual grain evolution: (a) grain size, (b) annealing twin density, (c) annealing twin density in individual grains as a function of equivalent grain diameter. 


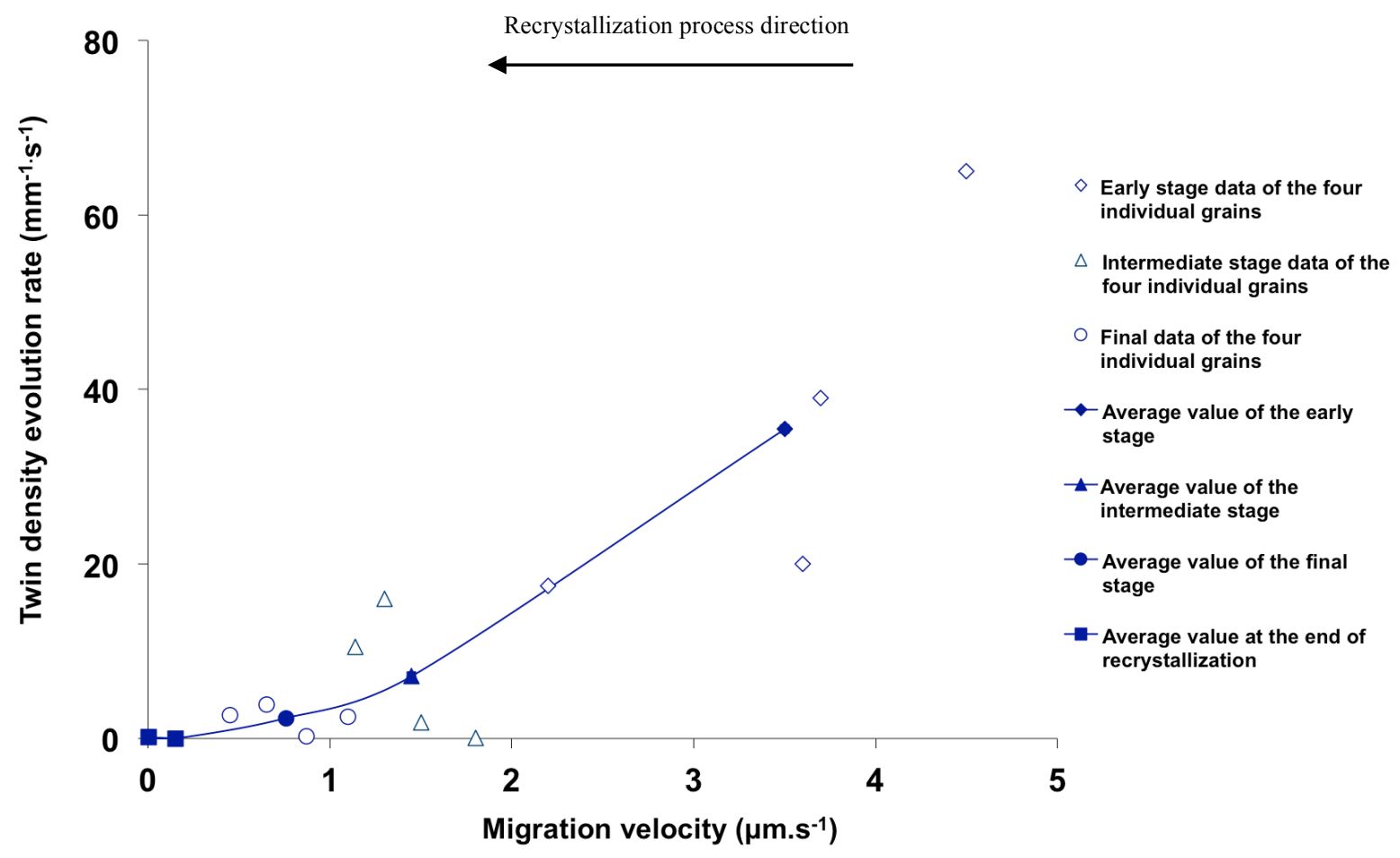

Fig. 7. Correlation of annealing twin density evolution rate with grain growth velocity 


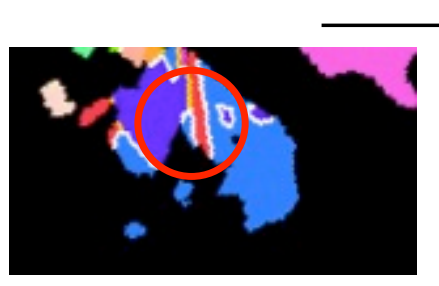

(a-1)

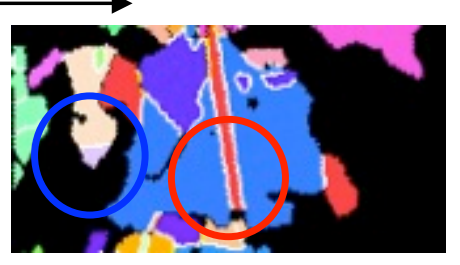

$(\mathrm{a}-2)$

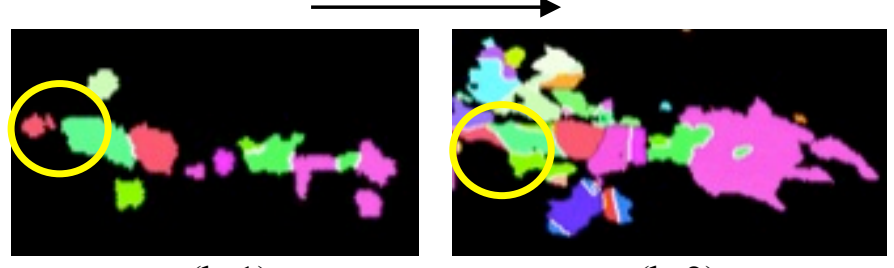

(b-1)

(b-2)

Fig. 8. Details of successive EBSD maps taken out of the in situ annealing series, showing different twin evolution mechanisms: extension of an existing twin in the section plane (red circle in (a)), generation (blue circle in (a)), propagation from below the analyzed section (yellow circle in (b)). Only recrystallized grains are shown (same orientation color code as in Fig.2). The black part represents the deformed matrix. In (b-1) the misorientation between the two grains surrounded by the yellow circle is $59.5^{\circ}$ along $<1-11>$. 


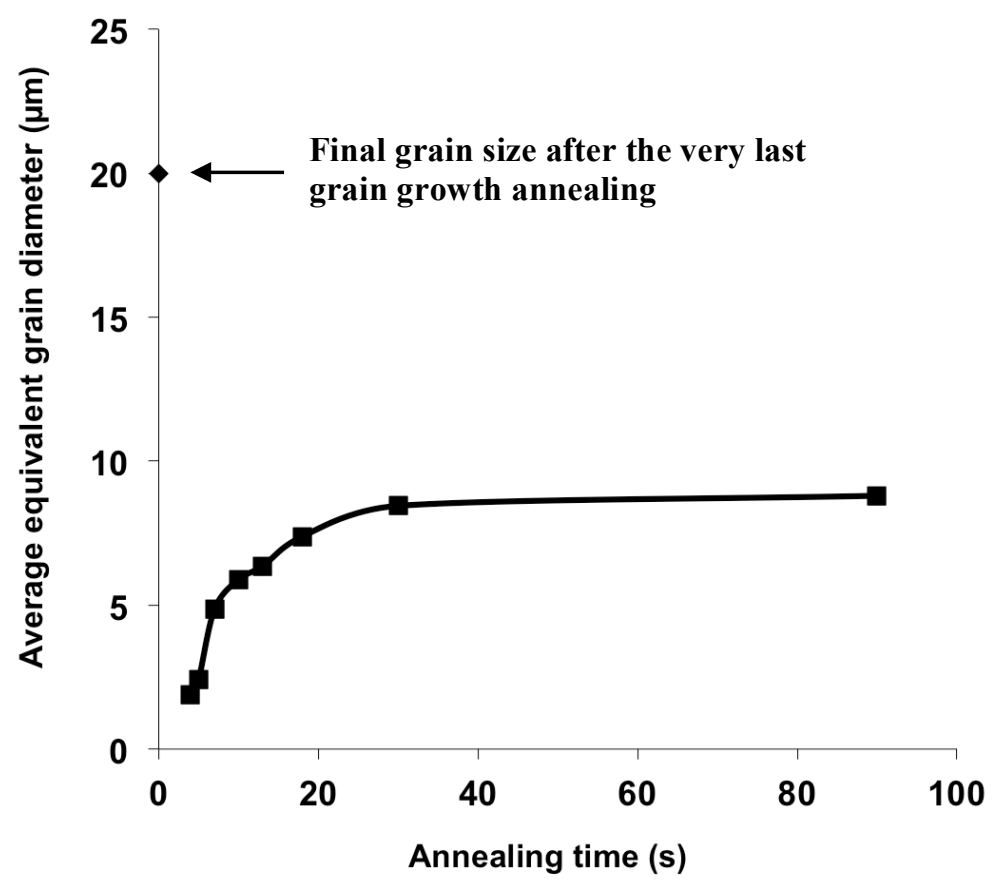

(a)

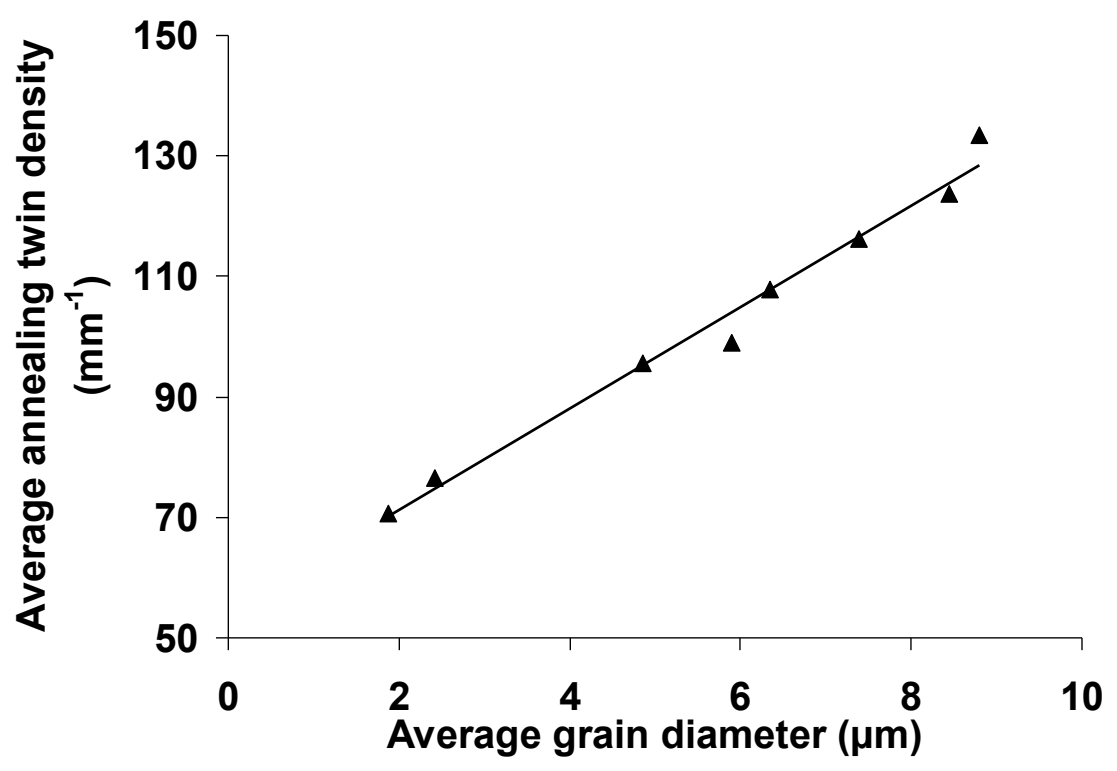

(b) 


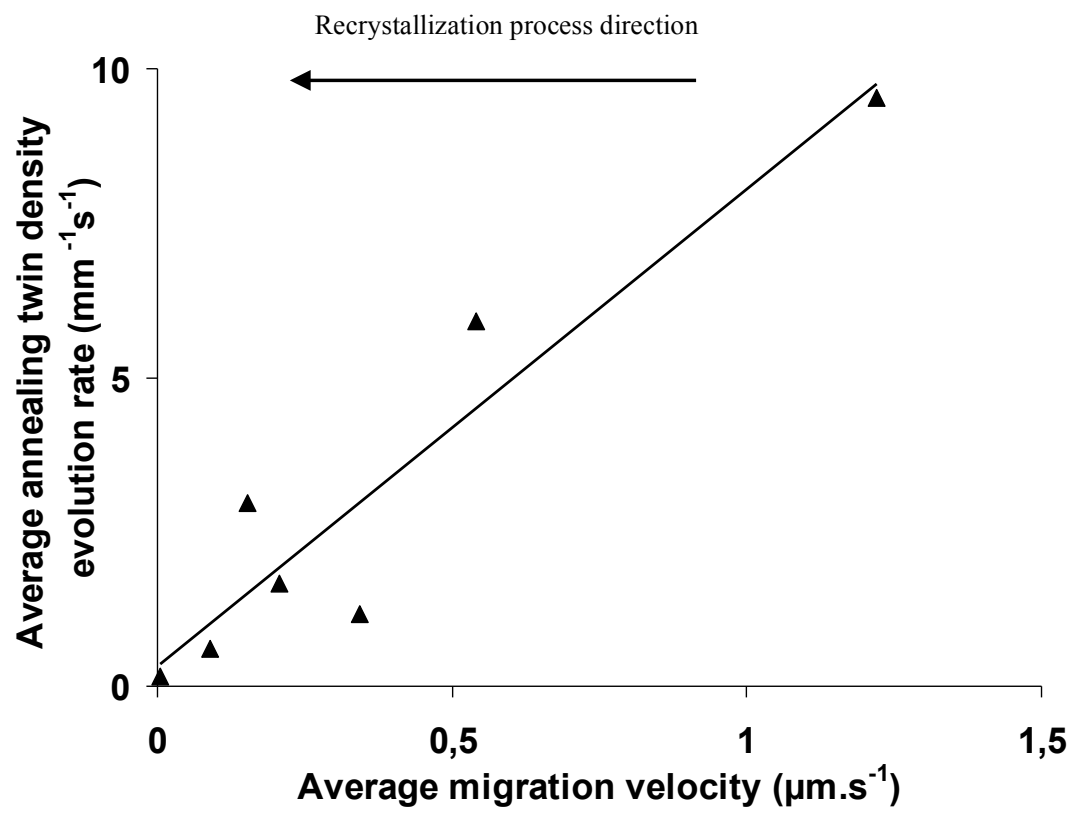

(c)

Fig. 9. (a) Average grain size evolution during recrystallization and after grain growth; (b) average annealing twin density during recrystallization as a function of average recrystallized grain size; (c) average annealing twin evolution rate as a function of average recrystallization front migration rate, showing that the twin generation rate is positively correlated with the migration rate. 


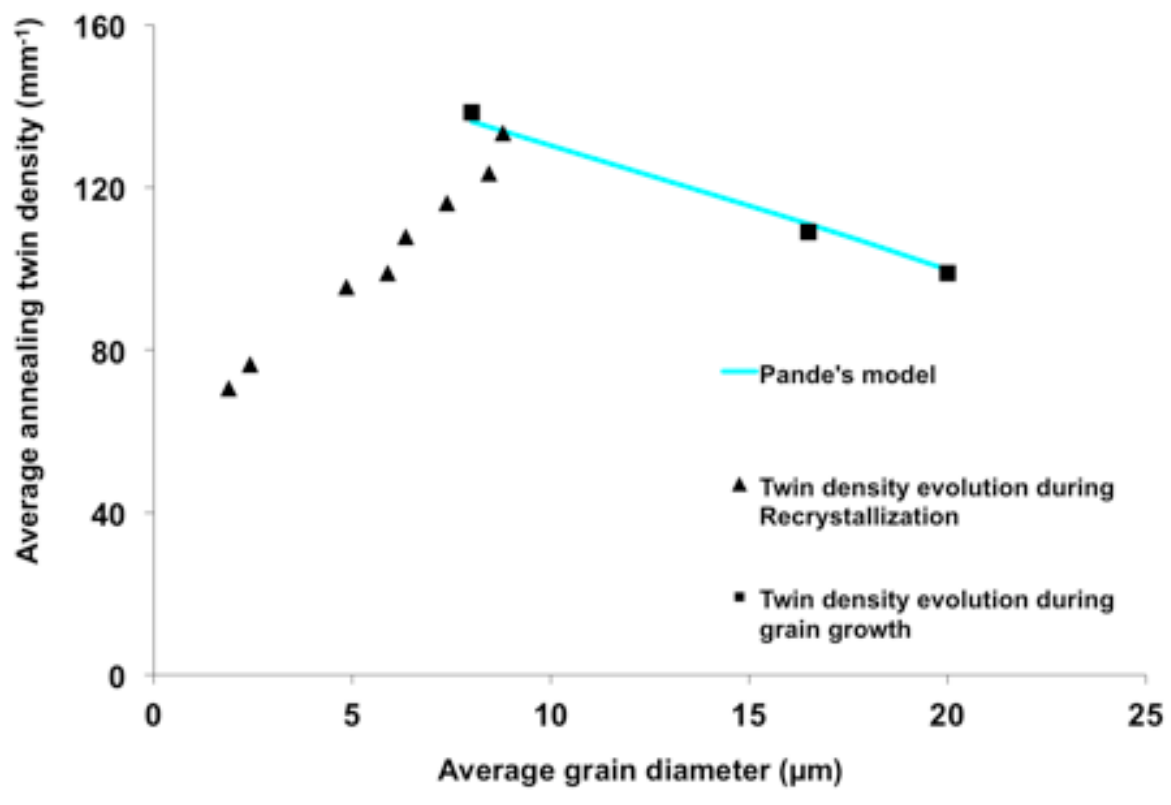

Fig. 10. Annealing twin density evolution in the grain growth regime for three different annealing times (Fig. 1(b)) as a function of average grain size (black squares). This relationship is opposite to the dependence that applies during recrystallization (black triangles). The final arithmetic average grain size of the recrystallization regime is bigger than the average grain size at the beginning of the grain growth regime because of the difference in the locations of the two considered snapshots. 

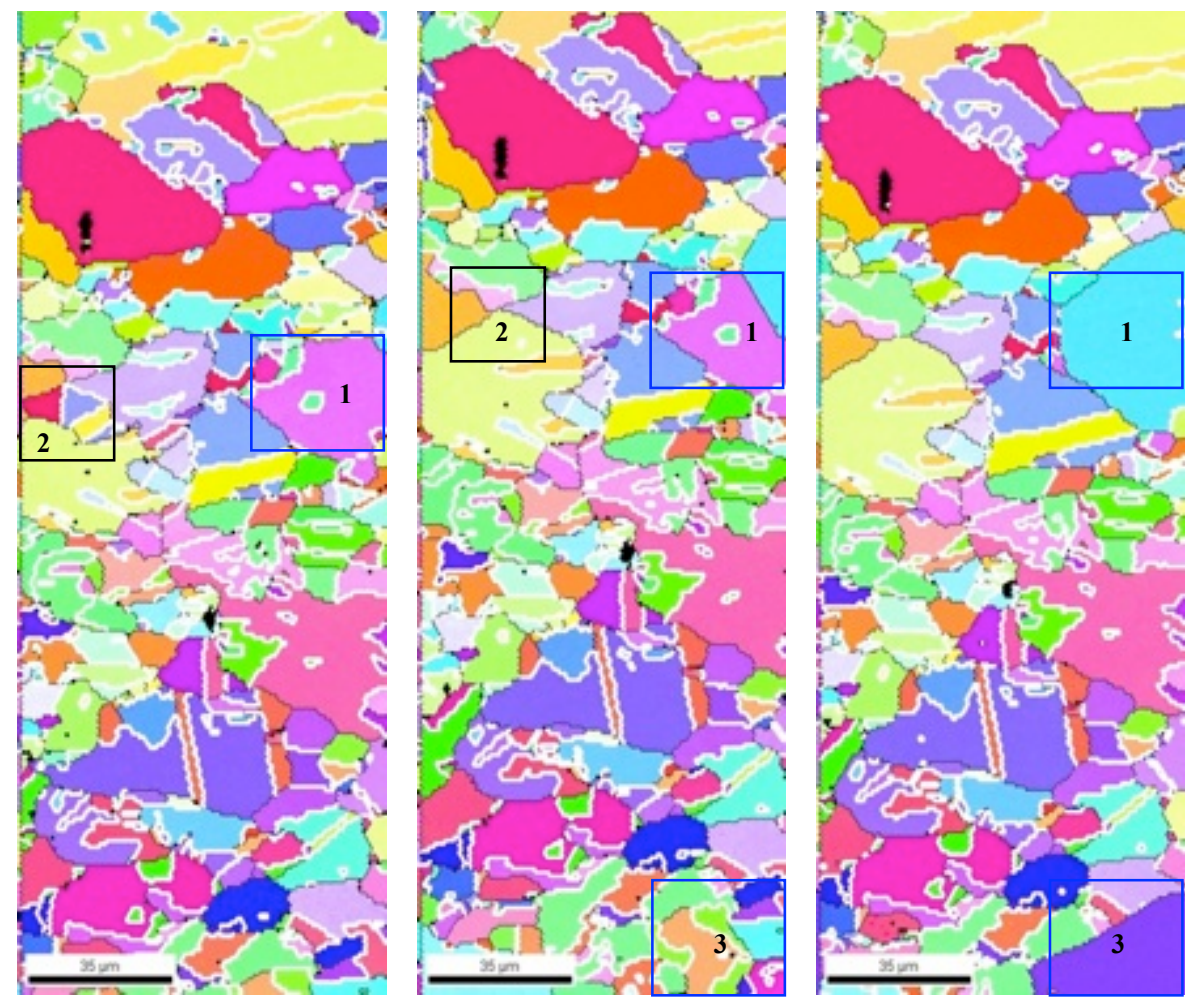

Fig. 11. In situ EBSD maps of the last three annealing steps in the grain growth regime. The black lines represent the general grain boundaries defined by a disorientation above $5^{\circ}$; the white lines denote the twin boundaries (same orientation color code as in Fig. 2). Note the (apparently) isolated grain (green) disappears as the pale blue grain grows in from the right. 

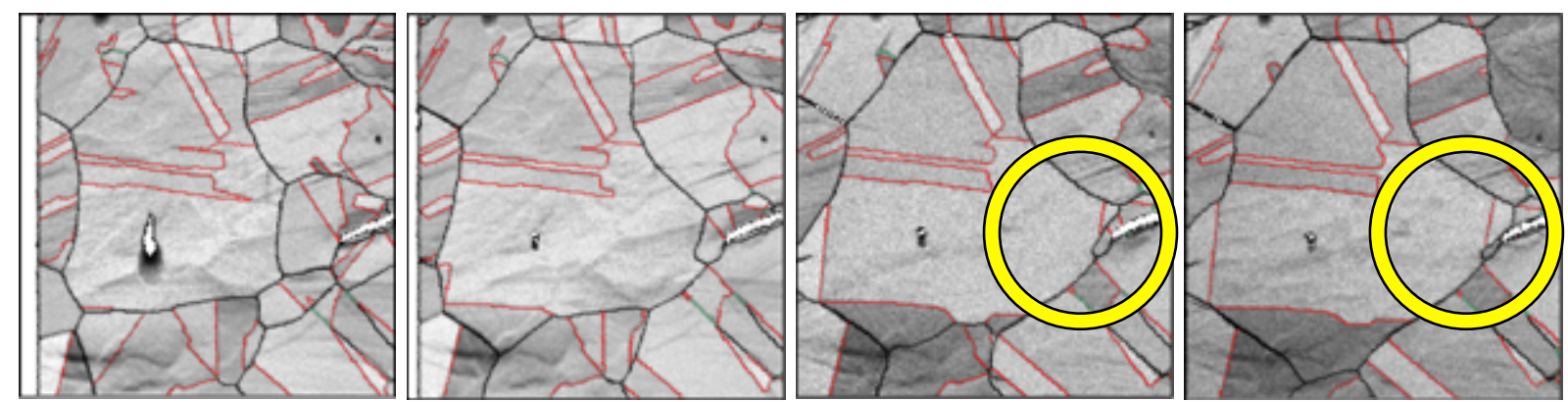

Fig. 12. In situ EBSD maps (grey scale according to the Kikuchi diagram quality) in 304L stainless steel during grain growth. The black thin lines represent normal grain boundaries defined by a misorientation bigger than $5^{\circ}$; red thick lines denote the twin boundaries; the yellow circle marks an annealing twin generation event. 

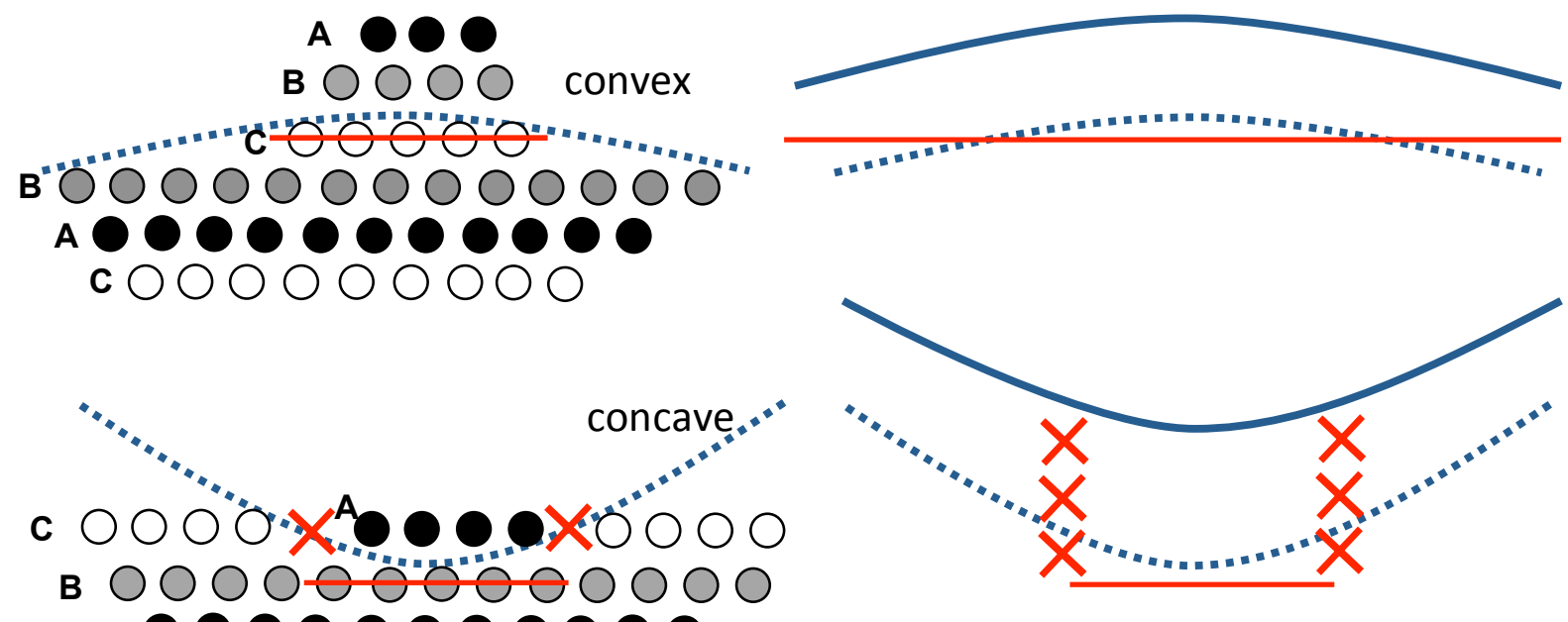

A 00000000000

c $\bigcirc \bigcirc \bigcirc \bigcirc \bigcirc \bigcirc \bigcirc \bigcirc \bigcirc$

Fig. 13. Annealing twin formation at convex or concave boundaries. Thick red lines represent coherent twin boundaries and incoherent twin boundaries are represented by the stacks of partial dislocations described by red crosses. 
